\title{
1. Introduction: unity and diversity in the law of sale of goods

\author{
Djakhongir Saidov
}

\section{GENERAL}

Trade is conducted by means of contracts for the sale of goods, normally regulated, domestically and internationally, by what is known as the 'law of sale of goods'. This body of law consists of the (state-made) principles and rules, contained in a piece of legislation, such as a code or a statute, and/or an international convention and cases. However, modern trade is characterised by a great diversity of products, industry sectors, commercial practices and trading and legal environments. This diversity has enriched enormously the ways in which sales contracts are governed today. The primary example of such enrichment is the emergence of a wide range of sources, emanating from the commercial and industry players, that can govern ${ }^{1}$ contracts of sales. With enrichment come challenges.

First, in the light of the diversity of trading contexts and multiple non-state made sources, what is and should be the purposes and roles of the (traditional) statemade law of sale of goods and do these purposes and roles continue to be relevant? Secondly, how should sales law interact with all such non-state made sources? Thirdly, sales law has traditionally been seen as a consolidated body of the law. This is primarily evident in the reliance by the legal community on an all-embracing code, statute, an international convention and case law, underpinning them. Such sources and instruments are believed to promote legal certainty and uniformity of governance, which, in turn, are seen as essential to commercial law and the business community. At the same time, the proliferation of other sources of governance, emanating from commercial players, means that a framework governing sales contracts is far from being confined to the traditional sales law regimes and, arguably, leads to the disintegration of sources of governance. Is it true to say then that we are witnessing competing forces at play within this framework: those pushing towards uniformity and consolidation, on the one hand, and those resulting in disintegration, on the other? If so, is this tension damaging for the governance of sales contracts and, ultimately, for the trade and trading communities? Finally, how should sales law grapple with the new legal issues, conceptual and practical, emerging as a result of fast-paced technological advancements, particularly in digital products and electronic communications?

These and related themes are the subject of this book that seeks to explore the nature and complexity of governance of sales contracts in the modern world. Its various

1 That is to say, influence, determine and/or regulate the contracting parties' rights, obligations and liabilities, both in the course of contractual performance and at the dispute resolution stage. 
chapters examine many aspects of sales law and practice, with considerable emphasis being placed on the diversity of: commercial contexts, in which sales contracts are made and performed; and sources governing such contracts. Every legal system or regime today has to grapple with the themes and questions highlighted in the previous paragraph. For this reason, this book largely has a comparative focus. Although some contributions concentrate on a particular legal system or instrument, they are still relevant to anyone with an interest in the law of sales. They identify difficult legal problems and possible solutions adopted by a particular legal system/regime, that may be useful to others, and explain the distinctive features of various trade sectors, commercial and transactional contexts. Modern trade is highly globalised, with a substantial bulk of sales being cross-border. This explains why the book is mainly concerned with international sales. Whilst the book may not definitively answer all the questions posed above, it examines them and their many ramifications extensively. All contributions are united in their pursuit of the common goal of understanding the challenges faced by sales law in the increasingly complex and changing world by exploring various topics from a wide range of perspectives, theoretical and practical. This approach seems best suited for tackling the main theme of this book: the unity and diversity in the law of the (international) sale of goods.

\section{UNIFORMITY AND STANDARDISATION OF GOVERNANCE}

\subsection{Sales Law Regimes and Their Ideal of Uniformity}

The forces of uniformity are evident across many layers of the framework that can govern a sales contract. As noted, the pursuit of legal certainty and predictability is almost universally recognised as a virtue and a major policy of modern commercial law regimes. Certainty promotes the ability of parties to rely on commercial contracts. It enables and facilitates the ability of businesses to plan their commercial activities. Arguably, certainty is also part of justice. Dr Lisa Spagnolo in her contribution to this book $^{2}$ takes a somewhat similar view by arguing that the reduction of uncertainty about the contracting parties' rights and obligations is one of the main economic functions of sales law and its default rules. She presents further reasons why certainty is desirable, whilst uncertainty is not:

Uncertainty surrounding the shape of enforceable obligations, potentially raises information costs and may encourage opportunistic behaviour where it transpires that a bargain is less profitable than anticipated by one side. A lack of legal predictability is especially problematic in international transactions where it is amplified by language and cultural differences. ${ }^{3}$

For all these reasons, well-developed sales law regimes aim to provide a reasonably clear and coherent set of rules and principles, consolidated through codes or statutes

2 L Spagnolo, 'Unification, Disintegration or Optimization: Purposes of Modern Sales Law', in this book.

3 Ibid. 


\section{Research handbook on international and comparative sale of goods law}

and/or case law. In short, it seems clear that well-developed sales laws aspire to the ideal of uniformity of legal treatment. Spagnolo suggests that such uniformity of treatment is beneficial because it provides 'an accessible path that shapes most important obligations in a predictable manner, thereby streamlining contract management for repeated cross-border transactions' ${ }^{4}$

Clearly, uniformity of treatment, legal certainty and predictability cannot be achieved simply by means of creating seemingly clear and coherent rules and principles. What is crucial is that these principles and rules should be interpreted and applied consistently. But given a wide range of scenarios and legal problems arising in practice and the need to achieve outcomes that are fair and reasonable as between the particular contracting parties, the consideration of certainty often clashes with the need for the law to be sufficiently flexible. As a consequence, one perennial question in commercial contract and sales law is how to strike a balance between the 'certainty' and 'flexibility' ends of the policy spectrum.

Nowhere is this tension more evident than in the law of damages for breach of contract, where one of the most intractable questions is whether damages must be assessed with reference to the loss that the injured has in fact suffered 5 ('concrete' assessment) or with reference to an 'abstract' formula, that presumes what the party's loss is in particular circumstances and is detached from the party's actual circumstances. Professor Andrew Tettenborn's contribution ${ }^{6}$ focuses on this dilemma between the concrete and abstract approaches to calculating damages that English law of international sales has long faced, with arguably mixed results that reveal real tension between the two approaches. Tettenborn, however, unequivocally sides with legal certainty and argues that English law should rely more extensively and forcefully on the abstract approach, based on presumed formulae, than it has done so far. This argument is largely driven by a strong sense of pragmatism:

International sales rely more than almost any others on a swift and reliable means of dealing with disputes. This means, among other things, the avoidance of protracted arguments on the measure of damages when things go wrong which is such a notable feature of English commercial law generally. To some extent this can be achieved by the use of skilful contract drafting and standard forms. But only to some extent: not everyone will use such forms, and there will be matters that inadvertently or otherwise are not governed by them. There is therefore much to be said, provided this is possible, for background rules laying down straightforward measures of loss. ${ }^{7}$

However, it would be an over-simplification to suggest that this argument is based solely on the author's preference for legal certainty. Tettenborn also agrees with what has become known as the 'performance interest' or 'substitutionary damages' conceptualisation and rationalisation of the abstract approach. According to it, a breach of contract results in the innocent party's not receiving an asset, to which it is

4 Ibid.

5 Bearing in mind this party's actual circumstances and conduct.

6 A Tettenborn, 'Abstract Damages in International Sale Contracts - When Should They Be Available?', in this book.

7 Ibid. 
contractually entitled, or in the damage to its contractual right to performance. As the author explains, these damages 'simply go to render performance complete, albeit in cash rather than in kind, and thus to some extent act as a kind of half-way house towards specific performance' and 'are measured by the (substitute) cash value of what the promisee did not receive' ${ }^{8}$ Because these damages function as monetary substitutes for contractual performance, the questions of mitigation and remoteness/foreseeability should, the author contends, be irrelevant, which further simplifies the damages assessment. These arguments cover the cases of non-delivery, non-acceptance and breach of warranty, but not, the author suggests, delay in delivery:

The Monday element of beans-on-Monday is not a money-equivalent asset in the same way as a promised $\$ 1,000$ parcel of beans which can be wholly or partly substituted with cash if no beans, or defective beans, are forthcoming. Instead, it refers to a mere modality of performance, which may or may not prejudice the buyer, according to the volatility of the price of what is being sold and the other circumstances of the sale. ${ }^{9}$

The pursuit of uniformity, and legal certainty that comes with it, has particular significance in international transactions, where the contracting parties are typically based in different countries, linguistic, cultural and legal environments. This significance is reflected in the text of the leading international instruments, such as the UN Convention on Contracts for the International Sale of Goods (CISG) that explicitly requires that it be interpreted and applied in a uniform manner. ${ }^{10}$ This requirement is central to the belief of the proponents of the movement to unify international commercial law that a uniform law promotes international trade by, amongst others, facilitating commercial exchange and reducing the negotiations, contract drafting and other transaction costs. This view is reflected in Spagnolo's contribution that elaborates on the benefits of an international uniform law:

A business which must perform obligations pursuant to many domestic laws in multiple contracts faces a far more onerous and costly contract management task than a business which has streamlined choice of law ... While parties may prefer their own law, this approach is not feasible if international counterparties all desire the same home ground advantage ... [F]urther ex post savings are engendered in dispute resolution by the use of uniform international sales law, since no expert witnesses are required and translations are often unnecessary. Enforcement costs are an important factor in lawyer choice of law. Moreover, risks of incorrect application by the forum are arguably lower than for application of foreign law. ${ }^{11}$

From the perspective of promoting legal certainty, it must be remembered that the CISG is relevant not just because of its own uniformity requirement. Generating legal certainty in international trade was one the main reasons for creating the CISG with a

8 Ibid.

9 Ibid.

10 See Art 7(1) CISG: 'In the interpretation of this Convention, regard is to be had to its international character and to the need to promote uniformity in its application and the observance of good faith in international trade.'

11 Spagnolo (n 2). 
view to facilitating trade. ${ }^{12}$ Although there is a considerable amount of scholarship on the CISG, much of its focus is on assessing the Convention's substantive aspects, comparing them with their domestic counterparts and analysing whether courts and tribunals worldwide have managed to approach the Convention's ideal of uniform interpretation and application. Professor Ulrich Schroeter's chapter, ${ }^{13}$ in contrast, steps back from the Convention's detailed provisions and instead identifies and articulates, what in his view, are its key purposes. It is only by understanding fully what the CISG seeks to achieve that the legal community can assess and appreciate whether the Convention can be seen as a success story. Schroeter is sceptical about the significance of what he calls the Convention's 'political purposes', set out in its preamble. The focus, this author suggests, should be on 'commercial-transactional' purposes, which are to: provide an 'acceptable' and 'pragmatic' set of default rules for international transactions; offer 'the best solutions' for cross-border commercial transactions; contain a well 'balanced' set of rights and obligations for buyers and sellers; increase certainty and predictability for commercial parties. Schroeter does acknowledge the compromises that the Convention's drafters had to make, the impossibility (for the CISG and national legal systems alike) of achieving perfect uniformity and that promoting and maintaining certainty and predictability will be an ongoing task. Nevertheless, the chapter concludes that, all in all, the commercial-transactional purposes of the CISG have been achieved, which means that, based on the stated criteria, the CISG is a success.

Here are some of the reasons for Schroeter's conclusion. As regards the 'acceptability' test - defined as existing if the CISG is 'viewed by commercial parties as a compromise that is preferable to the application of foreign domestic law'14 - the chapter points to the evidence, based on published case law, that this acceptability has been achieved. In fact, the author suggests that the degree of acceptance of the CISG is on the increase. Noting that the Convention's drafters were driven by pragmatism, the chapter characterises the Convention's provisions as based on 'simplicity, practicality and clarity', all of which promote certainty and make the CISG user friendly: '[i]t is expressed in the simple phraseology of commerce and free of legal short hand, free of complicated legal theory and is easy for business persons to understand'. ${ }^{15}$ And why, the reader may ask, should the CISG be seen as offering some of the best solutions for cross-border legal problems? Schroeter's answer is, in part, that the Convention's solutions were tailor made for the particular needs of international trade:

[a] purpose pursued by the drafters ... was not to settle for the lowest common denominator. They rather attempted to combine the best solutions suitable specifically for cross-border transactions, in contrast to those found in many domestic laws of sale primarily designed for domestic transactions. The resulting rules of the UN Sales Convention have widely been

12 See the preamble of the CISG.

13 UG Schroeter, 'Has the UN Sales Convention Achieved its Key Purpose(s)?', in this book.

14 Ibid.

15 Ibid. 
acknowledged as being in accordance with commercial practices and the needs of international trade, as well as being specifically tailored to international (as opposed to domestic) sales transactions. ${ }^{16}$

\subsection{Standardising Governance through Industry Sources}

The standardisation of governance of transactions has been pursued equally vigorously by the business world. In general, standardisation creates a common platform of mutual expectations for businesses in a particular industry or trade generally, helping individual businesses plan, manage, rationalise and possibly improve their activities, reduce costs of negotiating and drafting contracts, settle and avoid disputes. ${ }^{17}$ There are many areas evidencing such standardisation by the business world, of which the most prominent sources are: (1) standard form contracts, adopted by industry bodies/ associations, international organisations or individual companies; (2) the Rules and Codes adopted by industry bodies or trade associations, normally incorporated in their standard form contracts; (3) the so-called 'soft law' (non-legislative) instruments, such as the INCOTERMS or Uniform Customs and Practice on Documentary Credits (UCP $600)$, produced by international non-governmental business organisations, such as the International Chamber of Commerce (ICC); (4) trade usages and customs in specific trade sectors/markets or in general trade; (5) technical and ethical standards, adopted by industry bodies/associations/coalitions. Except for the latter source, extensively explored elsewhere, ${ }^{18}$ all the others are examined in this book.

The first industry source in the above list, standard form contracts, is explored in two of this book's chapters. Professor Clayton Gillette's chapter ${ }^{19}$ tests a claim that standard form contracts normally contain efficient or optimal terms. ${ }^{20}$ Whilst acknowledging the (already noted) ${ }^{21}$ benefits of standardisation by means of standard form contracts, Gillette shows that there are areas where and reasons why standard form contracts may be inefficient and their terms may be suboptimal. The factors giving rise to inefficiencies include: the parties with market power, who may want to assert it by shifting risks to their counterparties despite their being in a better position to bear those risks; ${ }^{22}$ failure of contracting parties to read the terms of standard form contracts, which happens, as this chapter points out, ${ }^{23}$ in commercial contracts as much as it does in consumer contracts; the aspects of 'political economy', such as where a trade association has incentives to generate terms in standard form contracts that are less than optimal or where the dynamic within a group drafting a standard form contract is

\footnotetext{
16 Ibid.

17 For a more detailed discussion of the benefits of standardisation in the context of conformity of goods, see D Saidov, 'Standards and Conformity of Goods in Sales Law' [2017] LMCLQ 65, 68-9.

18 See ibid.

19 CP Gillette, 'Are Commercial Standard Form Sales Contracts Efficient?', in this book.

20 An 'efficient' allocation of risk is defined by Gillette as 'an assignment of transactional costs and risks consistent with each party's capacity to bear them' (ibid).

21 See the main text, accompanying $\mathrm{n} 17$.

22 Which, based on the definition in $\mathrm{n} 20$, makes such standard form contracts inefficient.

23 With further references.
} 


\section{Research handbook on international and comparative sale of goods law}

driven by the desire for cooperation, which may result in a vague language, reflecting a compromise, with difficult matters left unaddressed; the so-called 'lock-in' effects and 'stickiness' of standard form contracts that hinder the required updating or revision of standard form contracts. ${ }^{24}$ These areas of or reasons for inefficiencies will not always be present and will only be relevant in a certain environment that will 'cause them to appear in suboptimal forms'. ${ }^{25}$ For example, the lock-in effects may well be prevented by a newly revised standard form contract being introduced by an authoritative trade association:

Where a trade association drafts a [commercial standard form contract] that is considered authoritative within the network, there can be a high degree of assurance that the innovative term will be widely used because all members reflexively use the most recent version of the association's form. Thus, any individual prospective adopter has reason to adopt the new term because there is assurance that others will act similarly, that is, that the new term will also enjoy positive network effects. ${ }^{26}$

Gillette also identifies the terms that appear to be inefficient, but may turn out to be efficient ('false inefficiencies'). Take a contractual term that is general or vague which may seem inefficient. The chapter argues that such terms may in fact promote efficiency by reducing drafting costs (particularly where they would otherwise exceed the ex post performance costs) or signalling some broad standard of performance, expected of a contracting party. Vagueness is viewed by the author as potentially 'a useful tool in an optimally drafted contract that involves parties who face uncertainty about how the future will affect their project, or who are contracting about nonverifiable tasks' ${ }^{27}$ Bearing in mind both the efficient and non-efficient features of standard form contracts, as well as false inefficiencies, Gillette prefers a textual, as opposed to a 'contextualist', approach to interpreting standard form contracts. The former promotes consistency and standardisation, reinforced by judicial interpretation having precedential value or influencing subsequent decisions concerning the same standard form contracts. The latter, in contrast, can lead to inconsistent interpretations, undermining the certainty and uniformity that standard form contracts are intended to provide. Gillette reaches the following broad conclusions:

if one concludes that markets, albeit imperfect, will work well enough that [commercial standard form contract] terms will tend to entail a relatively efficient risk allocation in commercial transactions, and that ad hoc inquiries could generate both false positives and false negatives for efficient terms, then perhaps the best strategy is to presume efficient terms in the absence of clear evidence to the contrary. For drafters, that might mean reluctance to alter the terms of [commercial standard form contracts]. For commentators, it might mean

24 As the chapter explains, the lock-in effects can be caused by various factors, such as: intrafirm dynamics, leading to inertia; or 'network effects', whereby the benefits of new technology or other developments can really be obtained and increase if they are accepted by and within the network of the relevant actors.

25 Gillette (n 19).

26 Ibid.

27 Ibid. 
reserved criticism of the significance or implications of questionable terms. And for enforcers, it might mean interpretation and application of the plain meaning of the terms as written. ${ }^{28}$

Professor Michael Bridge's contribution ${ }^{29}$ provides a detailed examination of standard form contracts in the commodities trade with the focus being on CIF and FOB contracts, produced by the Grain and Feed Trade Association (GAFTA) and the Federation of Oils, Seeds and Fats Association (FOSFA). The majority of sales contracts in the commodities trade, characterised by high price volatility and fluctuating markets, are made for the purpose of speculation. That is why much of the trade is conducted in 'strings' of traders and contracts. The 'strings structure' of transactions requires a high level of standardisation to enable and facilitate the contractual activity. Bridge highlights another factor pushing for standardisation, namely, 'the concentrated destination of goods crossing the Atlantic from North and South America in favour of the northern European bulk ports close to the River Rhine'. ${ }^{30}$ The standardisation in this trade sector manifests itself in the standardisation of: contracts, resulting in a very frequent and extensive use of standard form contracts, such as FOSFA and GAFTA standard form contracts; documents; goods and the standards governing their 'conformity' (namely, their description, quality, methods of inspections and other specifications and aspects); 31 'trade terms' (that are primarily concerned with the seller's delivery obligations, passage of risk of loss of/damage to the goods, the price structure); and the applicable law, which is almost invariably English law, with English case law on trade terms being an integral part of the meaning of standard form contracts in many commodities trade sectors.

The Rules of trade associations are addressed in several contexts, ${ }^{32}$ including that concerned with the question whether they can amount to a trade usage. ${ }^{33}$ Thus, Professor Djakhongir Saidov's contribution ${ }^{34}$ notes that a contracting party may rely on the Rules of a trade association as evidencing the existence of a trade usage in a relevant sector and that this question is relevant where the Rules do not form part of the contract. This contribution argues that such reliance on a trade association's Rules would be unjustified because by contracting on different terms to those in the Rules, parties must be taken to have intended to exclude the Rules. In the absence of factual evidence $^{35}$ that the Rules were intended to reflect an existing trade usage in the relevant sector, the Rules of a trade association cannot evidence a trade usage. More generally,

28 Ibid.

29 MG Bridge, 'CIF and FOB Contracts in English Law: Current Issues and Problems', in this book.

30 Ibid

31 In particular, Bridge underscores the role in achieving standardisation of some national inspection agencies, 'which determine in advance the technical standards that the goods must reach in order to be classified under numerical heads of quality' (ibid).

32 See also the following paragraph in the main text where trade associations are discussed in connection with the INCOTERMS.

33 The arguments in this paragraph are equally applicable to standard form contracts, as is made clear in D Saidov, 'Trade Usages in International Sales Law', in this book.

34 Ibid.

35 Such as that based on the drafting history and context of the relevant rules. 


\section{Research handbook on international and comparative sale of goods law}

Saidov suggests that the proliferation and use of the trade associations' standard form contracts and/or Rules 'largely marks the end of [trade usages] in these sectors' ${ }^{36}$

Professor Juana Coetzee's chapter ${ }^{37}$ is dedicated to the examination of the INCOTERMS, a 'soft law' code on international trade terms, ${ }^{38}$ and, specifically, to their role and function of standardising the governance of international trade to the extent covered by their scope. Coetzee demonstrates that the INCOTERMS have been performing this function with some success:

The results show that the Rules are used for a wide variety of goods, including wet and dry cargo, but that a significant number of contracts are for the sale of manufactured or produced goods, which would normally constitute containerized cargo. The sampled cases, furthermore, show that contract parties expressly incorporated the Incoterms ${ }^{\circledR}$ rules in sales contracts for machinery, equipment and other manufactured goods, agricultural produce, sea-food, foodstuffs, petro-chemical products, and even raw materials and commodities. Although traditional wet and dry commodity cargo did not feature significantly, it does not mean that these contracts are never concluded on the basis of the Incoterms ${ }^{\circledR} .{ }^{39}$

That said, this chapter recognises that standard form contracts of some major commodities trade associations often exclude the INCOTERMS in favour of English law on trade terms ${ }^{40}$ because of the certainty that comes with settled meanings and high level of detail that English law provides. Coetzee's view is that the frequent exclusion of the INCOTERMS in the commodities standard form contracts is not indicative of any weakness and calls for trade associations to use the INCOTERMS as doing so 'would send a message to the international mercantile community to make use of a uniform global standard instead of insistence on national standards'. ${ }^{41}$ This contribution also makes the point that success of the INCOTERMS as a standardising instrument depends on their effective relationship with other forms of standardisation and unification and finds that their symbiotic relationship with the CISG has already developed in practice.

Saidov's contribution focuses on another source of governance, emanating from the trading community - a trade usage, recognised and enforced by modern commercial law regimes to implement their main purpose of promoting trade. The latter is normally thought to be best achieved, if commercial law meets the needs and expectations of the

\footnotetext{
36 Ibid.

37 J Coetzee, 'Incoterms ${ }^{\circledR}$ and the Standardization of the International Sales Law', in this book.

38 'The Incoterms ${ }^{\circledR}$ are a set of international uniform, but optional, rules for the interpretation of three letter trade terms used in contracts for the international sale of goods, and which embody the most consistent business-to-business practices in the context of import-export transactions. The chief objective and purpose of the Incoterms ${ }^{\circledR}$ rules is to rationalize the number of trade term definitions by creating "a global standard rule of interpretation" for the use of merchants, national courts and arbitral tribunals in order to enhance legal certainty and reduce transaction costs. To that end, the purpose of the rules is similar to that of uniform law and other international instruments aimed at harmonizing or standardizing the law of international sales' (ibid).

39 Ibid.

40 A similar point is made in Spagnolo (n 2).

41 Coetzee (n 37).
} 
business community. A trade usage - a pattern of behaviour or a norm developed by business persons that results in standardising governance of sales transactions - is seen as a natural concentrate of such needs and expectations. By recognising a trade usage (a usage incorporation strategy), commercial law gives effect to them and aligns itself with commercial reality. Despite this significance attached to trade usages, Saidov takes the view that trade usages are in decline as the trading communities prefer to rely on industry sources that are much more formalised, detailed and comprehensive than fragmented trade usages. Drawing on the experience of the CISG, English law and the US Uniform Commercial Code, this contribution demonstrates a number of shortcomings in the way courts and arbitration tribunals worldwide have dealt with the preconditions for the applicability of a trade usage. As a result, there is a real danger that sales law has been promoting a 'fiction' or 'phantom' trade usages, throwing the viability of the usage incorporation strategy in doubt. This chapter advocates limited scope for the legal concept of a trade usage in international sales, with trade usages having potential relevance and applicability outside trade sectors with well-established trade associations and/or standard form contracts.

\subsection{Trade Terms}

Trade terms and the INCOTERMS in particular have already been mentioned. However, trade terms are a distinctive feature of international (as opposed to domestic) trade $^{42}$ and play such a prominent role in standardising the legal and contractual language in international sales that they deserve a more focused consideration, which is afforded in this book. Bridge's contribution examines selected issues relating to FOB and CIF contracts governed by English law. English law on trade terms has largely developed against the backdrop of the commodities trade, which in turn is largely organised under the auspices of trade associations, such as the already mentioned GAFTA and FOSFA that standardise and facilitate trade within their respective sectors with their standard form contracts and sector-specific arbitration mechanisms. Put differently, it is probably fair to say that trade in major commodities sectors is, to a significant degree, 'self-governed'. But when disputes regarding the construction of standard form contracts do arise, it does in the end fall upon English law, the preferred governing law, to resolve them. There is therefore an intensely close inter-relationship between English law on CIF and FOB contracts, on the one hand, and the commodities trade with its standard form contracts, on the other. This point is underscored in Bridge's contribution:

The law concerning FOB and CIF contracts, at least as far as commodity sales are concerned, is overwhelmingly a law of construction of the particular standard form selected by the parties. If one thing more than any other typifies the development of the law in this area, it is the symbiotic relationship between the standard forms that are drafted by trading associations, in the case of dry contracts, often in a way that no lawyer would, and the courts that interpret those forms. ${ }^{43}$

42 Their primary relevance lies in international transactions, but this is not to say that trade terms are not used in domestic trade.

43 Bridge (n 29). 


\section{Research handbook on international and comparative sale of goods law}

Whilst English law on trade terms dominates in the commodities trade, trade terms in other types of contracts would normally be subject to the INCOTERMS. They will often be either explicitly incorporated in a contract, but even if not, courts and tribunals routinely invoke them to interpret a contractual trade term. Despite their practical significance and prominence, little scholarly attention has been paid to the examination of their substance and practical application. Coetzee's chapter addresses this gap by assessing a number of their key provisions. For example, this chapter provides a balanced evaluation of the definition of delivery - namely, that goods must be placed on board the vessel, as opposed to cross the ship's rail - in FOB, CIF and CFR contracts under the most recent, 2010, version of the INCOTERMS. On the one hand, this contribution suggests that this definition has the advantage of being aligned with current commercial practice and more equitable than the 'ship's rail' rule because the performance of the delivery obligation is not linked with 'an incidence of chance, such as whether a container that was dropped during loading operations landed onto the deck or the quay side'. ${ }^{44}$ On the other hand, there may be some uncertainty so far as the stowing, lashing and trimming obligations are concerned. Placing the goods on board the vessel is also the point of the passage of risk of loss of/damage to the goods under the INCOTERMS. Coetzee takes the view that there may also be uncertainty in terms of whether this rule was intended to be used in string sales, where CIF/CFR contracts are normally used. In any case, this author appears to doubt the appropriateness of any rule that deviates from international commercial practice insofar as the (retrospective) passage of risk in string sales is concerned.

Given the prominence of both English law and the INCOTERMS in international sales contracts, an interesting question arises as to whether there is a competition or some relationship between them. Coetzee answers this question in the affirmative. As regards possible competition, she finds that a number of courts and arbitral tribunals elected to apply English law even though there was express contractual incorporation of the INCOTERMS. Coetzee also takes the view that English law poses competition to the INCOTERMS as major commodities trade associations, as noted, often choose English law. At the same time, this chapter argues that the INCOTERMS can be used by English courts as an 'interpretational tool' when applying an English law understanding of a trade term. Specifically, the INCOTERMS may be found to evidence a custom or at least an existing trade practice, not amounting to a usage, both of which can be given force under English law.

Finally, the question of both conceptual and practical significance is whether the INCOTERMS can or should be invoked to interpret a contractual trade term where no reference is made to them. Whilst, as Coetzee and Saidov suggest, it is unlikely that the INCOTERMS exist as trade usages for the entire international trade, ${ }^{45}$ they (or some of them) may well constitute trade usages in a particular sector, in which case it may be appropriate to use the INCOTERMS to interpret a contractual trade term. Where they do not amount to a trade usage, it may be more appropriate to resort to the INCOTERMS as being 'a widely shared international understanding of trade terms' ${ }^{46}$

44 Coetzee (n 37).

45 The view shared by Coetzee.

46 Saidov (n 33). 
as argued by Saidov, along with other potentially relevant sources, such as the experience of domestic laws or arbitration case law on this trade term.

\section{THE DIVERSITY OF COMMERCIAL, TRANSACTIONAL AND LEGAL CONTEXTS}

\subsection{Commodities}

There is a great multitude of commercial sectors and transactional contexts in which sales contracts are made and performed. Because the particular features of those sectors/contexts and the business communities' needs and expectations within them vary greatly, many sectors or industries develop ways to govern themselves in a way that suits such needs and expectations. For example, as noted, many sectors within the commodities trade govern themselves largely by means of an institutional framework of trade associations, that often includes their respective Rules and arbitration mechanisms, and standard form contracts. However, some commodities sectors, such as the oil trade, do not have such an institutional framework, but still standardise transactional terms, structures and concepts by relying on standard form contracts developed by some major oil companies. ${ }^{47}$ These industry sources, and especially standard form contracts, reflect the particularities of the relevant market and the distinctive features and properties of the relevant commodity.

Take again the oil sales contracts, which have a number of peculiarities. As Bridge explains, the vessel nomination clauses in FOB oil contracts tend to be more elaborate and laycan periods are significantly shorter than those in the 'dry' commodities. There is often a requirement that 'the buyer's choice of vessel be passed back to the terminal, from party to party in the contractual string if there is one'. ${ }^{48}$ Because of the need to put in place special unloading arrangements, a CIF seller in oil sales contracts often has obligations regarding the arrival of the goods - such as estimated times of arrival of the cargo - that are anything but characteristic of traditional obligations of a CIF seller who does not undertake obligations as to the goods' arrival or discharge. ${ }^{49}$ Bridge further notes the desire of oil companies to have flexibility in deciding on the destination of oil in transit and avoid transhipment, which explains the use of the so-called 'basis clauses'. By virtue of them, the buyer at the end of the string is able to determine the eventual destination of the goods and the seller can make the carriage contract on terms, whereby the vessel can be ordered to proceed to a port within the range

47 See Shell's General Trading Terms and Conditions, at: https://www.shell.com/businesscustomers/trading-and-supply/trading/general-trading-terms-and-conditions.html, accessed 1 December 2018. See also Bridge (n 29) ('Standard forms are of course used in the oil trade but these are the forms promulgated by the oil majors and do not have the representative character of the forms promulgated by associations in the dry commodities trades that present the interests of all members').

48 Bridge (n 29).

49 Except for the so-called 'negative' duty of the seller not to interfere with or cause obstacles to the goods' arrival at the contractual destination. 


\section{Research handbook on international and comparative sale of goods law}

indicated in these clauses. Other features of oil contracts include: the seller's extensive rights to substitute cargoes; the preferred payment by letter of credit; the passage of property before the presentation of documents (and hence payment, given the extensive use of the documentary credit mechanism), ${ }^{50}$ namely, when oil reaches the first permanent hose connection on the vessel; ${ }^{51}$ the possibility of payment to be made against the presentation of a letter of indemnity, ${ }^{52}$ and not just against the bill of lading, as is usually the case in international trade.

\subsection{Other Transactional Contexts: Long-term Agreements and Global Supply Chains}

The intense diversity of terms and structures of sales contracts is demonstrated by contracts for the sale of natural gas. Although natural gas, ${ }^{53}$ just like crude oil, is a hydrocarbon whose chemistry is similar to oil, the differences in their physical nature means that their markets and contractual structures could not be more different, as explained by Marc Hammerson and Emma Richardson in their chapter. ${ }^{54}$ The need to maintain long-term financing of the transportation of gas via pipelines (the predominant means of gas transportation) requires the supplier of gas to have a committed long-term buyer, providing continuous cashflow to the supplier. Consequently, contracts for the sale of gas are long-term and typically individually negotiated contracts, as opposed to spot/short-term oil sales contracts based on standard forms. As Hammerson and Richardson show, in contrast with the oil, a global commodity, gas is a regionally traded resource that is priced in accordance with the contractually agreed mechanism, as opposed to an international benchmark index in the case of oil. The long-term nature and inter-dependence between the parties mean that the contracts are based on a continuous buyer-seller relationship. ${ }^{55}$ These contracts necessitate a considerable degree of flexibility, such as the periodic (annual) adjustment of the price with reference to an agreed formula or the buyer's ability to adjust quantities (in the light of the downstream demand) through nomination procedures, rather than fixed amounts to be delivered at specified dates. That said, the contractual stability is equally significant for the parties, particularly, the seller who, as noted, needs regular and stable cashflow. This need is implemented, amongst others, by the so-called 'take or pay' (ToP) clauses that require a buyer to take or pay for a minimum quantity of gas during the relevant calculation period. As Hammerson and Richardson state, the "purpose of ToP is to

50 This position is very different from a presumption drawn by English law that in CIF contracts the property is presumed to be intended to pass from the seller to the buyer upon the transfer of documents.

51 For a recent example of such a clause, see Euro-Asian Oil SA v Abilo (UK) Ltd Euro-Asian Oil SA v Credit Suisse AG [2016] EWHC 3340 (Comm); [2017] 1 Lloyd's Rep Plus 17.

52 See, eg, ibid.

53 'Natural gas refers to hydrocarbon deposits occurring in either a gaseous or mixed gaseous and liquid state, primarily consisting of methane' (M Hammerson and E Richardson, 'Long-Term Gas Sales Agreements', in this book).

54 Ibid.

55 And, for this reason, could presumably be characterised as 'relational' contracts. 
allow the seller to receive regular cashflow during the life of the project since if the buyer does not take the minimum specified quantity of gas it nonetheless is required to make a minimum ToP payment'. 56

This chapter also explains the difference between the natural gas 'depletion' and 'supply' contracts:

\begin{abstract}
A depletion contract refers to the sale of gas from an identified field until a point at which further production is no longer economic (i.e., the reservoir is depleted). The [gas sales agreement (GSA)] is therefore drafted to be field-specific and certain terms are heavily negotiated. In contrast, a supply contract is a GSA based on a fixed duration and annual contract quantity or fixed aggregate quantity. It is not exclusively linked to supply from a particular field ... Under a depletion contract (also known as a dedication contract), the buyer purchases gas until a particular field is no longer economic to continue production. The seller allocates the entire reserves of that field exclusively to the buyer who provides an assurance of a dedicated offtaker of gas. ${ }^{57}$
\end{abstract}

These differences pre-determine the use of certain specific provisions and the particular allocation of risks in each of the two types of contract. For instance, in a depletion contract the seller normally has the right to stop the supply of gas when the production becomes unprofitable. This right would typically be based on the so-called 'economic termination clause', 58 which, as the authors point out, is often heavily negotiated and sometimes disputed in practice. More fundamentally, the chapter makes clear that in depletion contracts, the parties share the production and reservoir risk, whereas in supply contracts it is the seller who largely bears performance risk.

Whilst the noted differences between the GSAs and oil sales contracts are sharp, the chapter further explains that they have narrowed in recent times, particularly in the developed countries due to a range of factors, such as: the liberalisation of the gas industries in those countries, creating the multiplicity of participants; the possibility of gas liquefication that leads to the expanded modes of transportation; the possibility of converting depleted gas fields and reservoirs into gas storage facilities, creating supply flexibility for gas producers whilst making buyers less dependent on production from a nominated field. In the authors' assessment, all these factors create 'conditions that encourage the commoditisation of gas and its legal corollary: contractual uniformity'. ${ }^{59}$ As a result, there are signs that the phenomenon of contractual standardisation increasingly features in the gas industry, as evidenced by the development and use of model form contracts by various bodies, most notably the Association of International Petroleum Negotiators (AIPN). Some of the key provisions of the AIPN model form on Gas Sales Agreement 2006 are explained and examined in this contribution.

Another type of a long-term agreement explored in this book is a power purchase agreement (PPA), an agreement with considerable global economic and developmental

\footnotetext{
56 Hammerson and Richardson (n 53).

57 Ibid.

58 See, eg, British Gas Ltd v Amerada Hess Ltd [2006] EWCA Civ 900.

59 Hammerson and Richardson (n 53).
} 
significance across both the developed and developing world. In his contribution, ${ }^{60}$ Patrick Wallace focuses on the factors that influence the structure and design of PPAs, some of which are similar to those of other long-term agreements, whereas some others are unique to PPAs. Electricity is not a traditional commodity: it is not tangible, not located in a single location and cannot really be stored. It is these features of electricity that largely explain why presently the supply of electricity is probably not deemed as a contract for the sale of goods under English law. Nonetheless, commercially it is not greatly different from a contract of sale and, as Wallace notes, similar questions to those asked of a conventional sales contract arise under PPAs. The likely inapplicability of sales law and the UK Sale of Goods Act 1979 (SGA) to PPAs results in the need for contracting parties to provide detailed regulation of all aspects of their transaction. The features that PPAs share with some other long-term agreements, such as GSAs, include: the need for considerable upfront costs; ToP clauses; ${ }^{61}$ or clauses (often referred to as 'adaptation clauses') providing for mechanisms for dealing with events arising subsequently to the conclusion of a PPA (during its lifetime) that, in the author's words, 'destabilize the economic and other assumptions that underpinned the original pricing and performance terms'. ${ }^{62}$

That said, PPAs are unique in a number of respects, as this chapter demonstrates. Thus, high volatility of an economic value of electricity ${ }^{63}$ and the processes used for determining when a power station must generate electricity lead to the reliance on a dual charge structure, a monthly 'capacity' charge and an 'energy' charge:

The key factor is that a power station will not necessarily be called upon to generate at all times and the decision on whether to run it will not be made by the generator. This means the generator will not normally want to make the recovery of its fixed costs and profit margin dependent on unpredictable and potentially subjective decisions by the system operator about whether to run the power station. Generators therefore normally seek a fixed monthly 'capacity' charge that covers these costs irrespective of actual use and a variable 'energy' charge that is paid for each unit of electricity the power station is required to produce and that is designed to recover only the short run marginal costs caused by actually generating - in practice, mainly fuel. ${ }^{64}$

Some other provisions specific to PPAs include those seeking to manage and allocate major risks, such as a fuel supply risk or a credit risk. Wallace analyses different

60 P Wallace, 'Long-Term Power Purchase Agreements: The Factors that Influence Contract Design', in this book.

61 It should be noted, however, that their rationale and functions are explained in this chapter as flowing from the long-term fuel supply contracts.

62 'For example, changes in environmental and other laws, and changes in the price and availability of fuel lead to cost changes' (Wallace (n 60)).

63 'From a commercial and legal perspective, the most important differentiating characteristic of electricity is ... the inherent volatility in its economic value and this is what has the strongest influence over the way in which long term PPAs are normally designed. This volatility is caused by the fact that, as a product, electricity is impermanent, cannot really be stored using current technology and therefore has to be produced in real time; and that business and domestic demand for electricity varies enormously between different times of day, between working days and weekends, and between different seasons' (ibid).

64 Ibid. 
contractual provisions and highlights those solutions that, in the author's view and experience, can tackle these risks most effectively. For instance, Wallace suggests that an effective approach to dealing with the 'fuel supply' risk is for the parties to characterise their agreement as one for service of turning fuel into electricity (an 'energy conversion' or a 'toll processing' agreement). He argues that this change in terminology:

can often achieve a major change in contractual risk allocation, because if it is adopted, the natural consequence for negotiations is that the parties will reach agreement on specific clauses that allocate all fuel supply risks to the offtaker; whereas if the agreement remains described as a sale and purchase, the natural assumption is that the generator organizes fuel supply and takes the resultant risks. Then the generator has to negotiate hard to transfer these to the power purchaser utility, even though the utility is arguably better placed to spread these risks across its customer base. This shows that, while the title the parties give to an agreement does not bind a court or arbitrator when analysing or characterizing it, adopting a particular title at the outset of negotiations can have important practical consequences for what is subsequently agreed. ${ }^{65}$

The need for long-term stability, a characteristic featuring in both GSAs and PPAs, characterises also sales contracts embedded in another major commercial and transaction context: namely, that of the global supply chains, examined in the contribution by Professor Fabrizio Cafaggi. ${ }^{66}$ Some data suggests that an estimated 80 per cent of global trade is connected with the international production networks of transnational corporations (TNCs). ${ }^{67}$ Cafaggi argues that sales transactions and contracts within global supply chains are very different in their character and functions to the more typical 'isolated' sales, with reference to which the sales law regimes have traditionally developed. For sales law, an individual sales contract is a 'unit of analysis', whereas in global supply chains, many legal and commercial issues should be dealt with having regard to the contractual relationships and their stability within the entire supply chain:

A contractual relationship is not merely a single contract between two parties. It includes the legal and social environment within which contracts arise and are performed. Within chains, contractual relationships constitute the organizational skeleton. They may be established between legal entities belonging to the same organization (for example, subsidiaries) or between independent entities (suppliers, distributors). ${ }^{68}$

This chapters identifies a number of distinctive features of transactions in global supply chains which require, in many respects, special legal treatment. These features include: (1) inter-dependence of supply chain members and the need for many, if not all, of them to coordinate their conduct and operations, including 'corrective' and 'collective' measures in order to remedy or deal with the consequences of a contractual breach;

65 Wallace (n 60).

66 F Cafaggi, 'Sales in Global Supply Chains: A New Architecture of the International Sales Law' in this book.

67 See UNCTAD, 'Global Value Chains and Development: Investment and Value Added Trade in the Global Economy', 16, available at: https:/unctad.org/en/PublicationsLibrary/ diae2013d1_en.pdf, accessed 1 December 2018. This source is also cited in Cafaggi (n 66).

68 Cafaggi (n 66). 
(2) the existence of 'chain leaders' (typically, TNCs), who issue and dictate which codes, standards or terms must be incorporated and govern all contracts within a chain, thereby effectively 'regulating' the entire supply chain; (3) extensive reliance on 'transnational' codes and standards, adopted by chain leaders and/or industry bodies/ coalitions/associations, and/or international inter-governmental or non-governmental organisations; (4) the prominence of not just the product-related requirements, but also of those concerned with the production process; (5) the frequent need for the seller's contractual performance to be monitored by a third party (certifier), not representing the buyer and driven by the chain leader's need to ensure and, if necessary, enforce compliance within the entire chain;69 (6) the need for and extensive incorporation of 'post-contractual' obligations, such as restraints of competition, protection of information and confidentiality, post-sale warranties, management of intellectual property rights.

All these features dictate, in Cafaggi's view, a different approach to that which sales laws normally adopt in respect of isolated sales. Sales embedded in global supply chains require the recognition of inter-dependence and promote stability of contracts within the chain. For example, there is a need for a duty to cooperate by the contracting parties. The remedies of damages, specific performance and termination, that feature prominently in isolated sales, have much less significance in the global supply chains' context, where priority must be given to corrective measures with a view to preserving stability with the chain. The sales law regimes must make it clear that the remedy of cure and its two forms, repair and replacement, must cover not just the productrelated obligations, but equally the process and design-related obligations. In short, Cafaggi advocates the need for a new international sales law 'architecture' to govern sales contracts within global supply chains. It can take two forms. One is to interpret the existing sales law regimes, such as the CISG, with reference to the special features of global supply chains. For example, the test of a 'fundamental breach' in Article $25^{70}$ - the main ground for enabling the innocent party to terminate the contract under the $\mathrm{CISG}^{71}$ - should be interpreted, Cafaggi contends, with reference to the effect of the breach not just on the buyer, but on the entire chain. The other, more radical, form

69 'Complex monitoring architectures, seeking to ensure compliance by remote partners, are partly driven by the fact that the chain leader is not a party to the contracts within the chain. Monitoring contractual performance is mainly performed by intermediaries ... [S]ome suppliers' codes explicitly provide for a third party's monitoring rights, whereas other codes simply confer monitoring rights to intermediaries, like certifiers. The features of standard setting, monitoring and enforcing contract rules within the chain are partly correlated with the organizational models of the chain leader. The rules are defined primarily by the chain leader at the centre with the increasing collaboration of procurement units at the local level. Different corporate governance models may affect the chain's regulatory architecture with various degrees of decentralized private regulation of contracts' (ibid).

70 Art 25 CISG: 'A breach of contract committed by one of the parties is fundamental if it results in such detriment to the other party as substantially to deprive him of what he is entitled to expect under the contract, unless the party in breach did not foresee and a reasonable person of the same kind in the same circumstances would not have foreseen such a result.'

71 The concept of a fundamental breach under the CISG is also relevant in other respects, such as: whether the buyer has the right to demand the delivery of substitute goods (Art 46(2)); whether the buyer retains its remedies despite the risk of loss of/damage to the goods passing to 
that the new architecture can take is the creation of an entirely new regime specifically designed for the global supply chains context. How the international legal and business community proceeds with the governance of this context remains to be seen.

\subsection{Digitised Products, Electronic Data and Communications}

Digitised products and electronic commerce/communications not only create a distinctive transactional context and environment, but also pose challenges, conceptual and practical, for commercial and sales law. One such challenge with which all modern sales law regimes have to grapple is whether contracts for the supply of digitised products, and software in particular, constitute contracts for the sale of goods. This question is important because the answer to it pre-determines whether the sales law in question is applicable to such contracts. If not, there may be uncertainty as to which rules and principles are applicable, as well as questions about the suitability of the applicable rules/principles for the effective governance of contracts involving digitised products. Professor Sarah Green's chapter ${ }^{72}$ analyses the current position of English law, whereby digitised material can only be categorised as 'goods' if it is contained on a physical medium. Noting the 'English law's tendency jealously to guard its hallowed definitions', 73 Green develops her critique of the considerable weight and role that English law attaches to 'tangibility', a key characteristic of the English sales law's traditional understanding of 'goods'. She argues that it is not tangibility, but the 'concreteness' of things - that is to say, 'their existence in the world independent of relationships between individuals' 74 - that should dictate what legal treatment should be afforded to a given transaction. The particular physical properties of a thing should not pre-determine the legal treatment it is afforded:

When we are trying to establish whether a particular thing should be subject to the law applicable to sales transactions, the essence of what we are asking is not what that thing looks or feels like ... What we really want to know is whether a particular interest in that thing can be transferred in exchange for money. In the digital age, a particular set of physical characteristics is no longer determinative of the way in which a thing functions as a legal object. It is not at all obvious, for instance, that the ability of something to be 'delivered online' ... renders it 'not capable of being owned as such'. Whatever the appearance of the physical manifestation of digitised material (and indeed whether or not it can be perceived with the unaided senses), it is concrete and not abstract. It has a form in the world, whether or not I or anyone else lays claim to it. It can thus be created, used, abused, moved and destroyed. ${ }^{75}$

Green's chapter further emphasises the arbitrary legal position, whereby the same type of a transaction will be afforded different legal treatment, simply depending on how the relevant material or product was acquired (for example, being on a physical medium or

the buyer (Art 70); the buyer's remedies in case of an anticipated non-performance and in the context of an instalment contract (Arts 72, 73(1) and (2)).

72 S Green, 'Sales Law and Digitised Material', in this book.

73 Ibid.

74 Ibid.

75 Ibid. 
downloaded online). This chapter also addresses another potential obstacle to the digitised products being classed as goods, namely, the fact that a digitised material is typically 'licensed'. It argues that sales law 'prioritises the integrity of each discrete transaction over the promotion of ongoing transfer'. ${ }^{76}$ Therefore, in principle, the inability of a party, who acquired a digitised material, to sell it onwards should not affect the classification of the transaction by which this party acquired title to that material/product.

In addition to the widespread emergence and use of digitised materials, the past decades have witnessed the advancement in electronic recording and processing of information. Against the backdrop of this development, Dr Miriam Goldby ${ }^{77}$ explores several questions. One is whether the newly emerging information technologies are capable of performing the functions that the traditional 'paper' documents (particularly, documents of title) have performed, and possibly replacing the latter. If so, what qualities must information technologies/electronic data possess to be able to function as well as, or better than, the paper documents? In answering these questions, the chapter keeps in mind the requirements of English law concerning conformity of documents in CIF contracts. Another question that this contribution poses is whether the existing transnational instruments - that are concerned with conformity of documents/ documentary tender from the perspective of either the seller's obligations under sales law/contract (INCOTERMS) or the payment/security mechanisms, such as documentary credits (UCP600 and eUCP) - accommodate sufficiently the developments in information technology. In the light of the fast-evolving nature and fluidity of the commercial, technological and legal landscape in this area, it is too early to expect definitive answers to the complex questions posed by Goldby's chapter. Some helpful insights are nevertheless offered. For instance, as regards the first question, Goldby explains that some functions of paper documents can be performed by the new technology. Take a centralised registry (ledger), a single authoritative register of the relevant facts and rights maintained by a central service provider, or a 'distributed one, where each network participant has an identical copy of the ledger, a more recent development made possible by blockchain and other distributed ledger technologies (DLTs)' ${ }^{78}$ Goldby suggests that this system is capable of functioning as well as a paper bill of lading, 'the reliability of the data derives from the maintenance of the registry by an independent third party which can attest to the authenticity of any entries made in the registry'. ${ }^{79}$

The chapter goes further and contends that in some respects, such as countering fraudulent practices, the electronic data systems may well be superior to paper documents. This contribution conveys a sense that the information technologies infrastructure and, even more so, the existing legal framework have not yet ripened for the electronic data systems/documents to be able to take over the functions of paper documents. Looking into the future, however, the chapter sheds light onto the

76 Ibid.

77 M Goldby, 'Substituting Data for Documents - A New Meaning for "Conforming Tender"?', in this book.

78 Ibid.

79 Ibid. 
additional requirements of conformity of documents/documentary tender that may need to be developed for parties to transact effectively within the electronic data environment.

\section{INTERSECTIONS WITH OTHER AREAS OF THE LAW}

The complexity of governance of sales contracts is further evident if other areas of the law, with which sales law intersects, are taken into account. One instance of such an intersection concerns the widely used 'retention of title' (ROT) clauses that can fall within the ambit of not just sales law, but also the law of secured transactions and insolvency. These clauses are the focus of Professor Michael Schillig's chapter ${ }^{80}$ that examines how they are governed by English and German law in the context of cross-border insolvency, addressing also the conflict of laws aspects. As this chapter explains, the ROT clauses seek to protect the seller against the buyer's non-payment of the purchase price (a 'simple' ROT clause) or other monies owed ('all monies clause') by reserving the seller's ownership of the contract goods or by even extending that ownership to a new product, manufactured by the buyer using the contract goods ('manufacturing clause'). These clauses may even seek to extend security by attaching it to the proceeds or receivables that the buyer obtains from a sub-sale ("proceeds clause'). All these clauses are examined in detail in this contribution, which demonstrates the different legal treatment that one and the same scenario would receive under English and German law.

For example, in relation to an 'all monies clause', Schillig explains that such clauses would be given effect under English law, including where the buyer owes debts to companies associated with the seller. In contrast, under German law extending a clause to 'claims owed by the buyer to a third party, in particular an affiliate, subsidiary or parent company of the seller ... would be invalid'. ${ }^{81}$ In a similar vein, a 'manufacturing clause' under English law will most probably be regarded as creating a mortgage or charge, which will typically be void for a lack of registration (given the impracticality and high expense of registration) if the buyer is a company incorporated under the Companies Act 2006. According to German law, however, 'the manufacturer of a new movable corporeal thing will be the owner of that thing'. ${ }^{82}$ This means that, in principle, 'the buyer would, by operation of law, become the owner of newly manufactured goods' and the ROT 'in the raw material would be extinguished'. Schillig's comparative examination reveals much complexity and uncertainty in terms of legal treatment of all types of ROT clauses. Schillig expresses his doubts about the possibility of any harmonisation efforts in this area:

80 M Schillig, 'Insolvency Treatment of Retention of Title Arrangements in Cross-Border Transactions', in this book.

81 Ibid.

82 Ibid. 


\section{Research handbook on international and comparative sale of goods law}

It seems unlikely that in the short- or medium-term greater convergence can be achieved in the treatment of retention of title clauses in their various forms. The harmonisation of substantive law in this area faces a formidable obstacle in the disparity of (personal) property law in common law and civil law countries, and even among different civil law systems. ${ }^{83}$

This means that legal community will have to continue to navigate through a vast array of legal complexities that will damage, Schillig concludes, the parties' ability to plan their transactions and, ultimately, the free flow of trade.

Another area which not only intersects, but also arguably exerts a considerable influence on the development of sales law is arbitration law. Sir Richard Aikens' chapter $^{84}$ explores a symbiotic relationship between, on the one hand, the English law of international sales and, on the other, arbitration and control of the arbitral system by the courts. The chapter shows that much of the development of early sales law was integrally interconnected with an arbitration system of dispute resolution. As Aikens states, 'throughout the 19th century the huge growth in trade and so sales contracts ... led a concomitant reliance on arbitration by merchants to resolve their disputes'. ${ }^{85}$ Importantly, it was the availability of the procedure known as the 'Special Case' which enabled courts to review issues of law, but was abolished in 1979 - that contributed significantly to the development of the English law of international sales. The new law, enshrined in the UK Arbitration Act (1996), has restricted the scope for appeals on points of law from arbitration awards and Aikens underscores the danger that this may have 'stultified' the development of the English law of international sales. ${ }^{86}$ The chapter emphasises that whilst it is still the case under the 1996 Act that only issues of law (and not of fact) can be appealed to courts, courts retain the power to decide how a particular issue is to be characterised. But so will the tribunal of fact have much power, as its findings of 'fact' will have an impact on the formulation of an issue of 'law' and how the latter will be approached and decided by the court:

The shape of the issue of law that may ultimately be decided by the courts on appeal from an arbitral tribunal has always depended and continues to depend on the findings of fact of that tribunal. What those findings are has a direct impact on the way the court is able to approach the point of law that may be in issue. Thus, to take one simple example, an issue on whether a buyer is entitled to reject goods will depend on what facts are found relating to the goods and the circumstances in which the buyer attempted to reject. Or, to take another, the extent to which a court might be able to conclude that there is a 'custom of the trade' will be determined by the findings of fact about what is usual in a trade. ${ }^{87}$

\footnotetext{
83 Ibid.

84 R Aikens, 'The Impact of Arbitration on the Development of International Sales Law', in this book.

85 Ibid.

86 Ibid. Some commentators go further and suggest that English sales law may have substantially gone 'underground' as a result of 'drying up' of sales law cases that go to courts (the remark was made by Professor Michael Bridge at the conference on 'Unity and Diversity in the Law of the International Sale of Goods', held at King's College London, 16-17 April 2018; it is also referred to in Spagnolo (n 2), footnote 87).
}

87 Aikens (n 84). 
There is, therefore, little doubt that the law of arbitration has a real impact on the development of the substantive international sales law. The old 'Special Case' has boosted its development, but the modern arbitration law may well have hampered it.

Sales law also closely intersects with the law of trade finance. In particular, documentary credits have traditionally been one of the most widely used methods of payment in sales contracts, providing security to both sellers and buyers. Under the documentary credits mechanism, the seller is able to part with the goods before receiving the payment from the buyer in the knowledge that it will receive payment from a bank ${ }^{88}$ against a complying documentary presentation. The buyer in turn gets an assurance that the payment will only be made against complying documents, which would evidence the seller's performance of its key duties (or most of them) under a sales contract. By receiving the documents, the buyer is also in the position to resell the goods. The documentary credits mechanism thus balances the interests of both parties, facilitating cross-border trade particularly where the contracting parties do not know whether each of them is trust- or creditworthy. Christopher Hare's contribution ${ }^{89}$ explores the documentary letter credit (as governed by the ICC's UCP 600) as it stands today and challenges the traditional perception of its dominant role as a trade finance instrument. Whilst emphasising that standardisation, consolidation and harmonisation of payment methods and related matters are 'the leitmotifs' of the development of documentary credits and the UCP 600, this chapter nevertheless argues that:

this high period of uniformity and consolidation appears to be on the wane, with trade financing entering a phase of disintegration and disaggregation. This impulse appears to have a number of sources: first, from within commercial/documentary credits and the UCP itself, as what were once key strengths become obstacles to the letter of credit's future prospects; secondly, from the increasing regulatory burden imposed on banks in the conduct of their business; thirdly, from financial innovation and the alternative uses to which letters of credit are likely to be put in the future; fourthly, from competitor payment mechanisms that are more responsive to modern trading conditions and technological innovation than an essentially paper-based payment system; and, finally, from the recent rise of nationalism and protectionism that seeks to challenge globalisation and its established structures. Each of these will be considered in turn..$^{90}$

So far as the first source - namely, the weaknesses inherent in the UCP's legal nature - is concerned, Hare identifies many reasons that cause disruption of the unity or disintegration of the UCP regime. These include: (a) gaps in the UCP coverage that encourage forum-shopping which eventually results in conflicting case law; (b) differences in the way civil and common law courts have generally viewed the UCP's legal nature - with the former attributing the UCP something approximating a 'normative status', whereas the latter treating them as an optional regime - that result in different approaches to such issues as applicability of the UCP; (c) the absence of a supranational body to monitor and promote their uniform application that inevitably

88 Typically, an issuing bank that 'issues a credit at the request of an applicant', such as the buyer (or 'on its own behalf') or a confirming bank that 'adds its confirmation to a credit upon the issuing bank's authorization or request' (see 'Definitions' in Art 2 UCP 600).

89 C Hare, 'Consolidation and Disintegration in Trade Finance' in this book.

90 Ibid. 


\section{Research handbook on international and comparative sale of goods law}

leads to various provisions and aspects of the UCP regime being interpreted differently by different courts; (d) the danger of legal techniques, such as implication of terms, used by courts to fill gaps in and/or inject more detailed meaning into the UCP regime; (e) the banks' discretion in assessing documentary compliance; (f) the treatment by some courts of the buyer's opening of a letter of credit as no more than a conditional payment (that in itself does not discharge the buyer's obligation to pay), creating perception that letters of credit are 'somewhat less than absolute in nature' 91 and damaging their utility and harmonisation aspirations and effect; (g) and even the 'autonomy principle', 92 usually seen as a cornerstone of documentary credits. In relation to this principle, Hare contends that:

by viewing the autonomy principle as something unique, letters of credit have themselves similarly been treated as something unique and accordingly have traditionally tended to be doctrinally isolated from general developments in private law, such as the law of subrogation, unjust enrichment and contractual damages and doctrines. Such isolation from domestic legal principle has had the advantage of encouraging uniformity of principle, since the operation of letters of credit are effectively protected from being 'tainted' by domestic law notions. More recently, however, the English courts have started to push back against this legal isolation and have increasingly subjected letters of credit to more general private law analysis. Whilst this is likely to increase the internal consistency of a particular legal system's domestic law, this is likely to increase the tendency towards legal fragmentation of letter of credit law across different jurisdictions. ${ }^{93}$

\section{SALES LAW AND DIVERSITY OF SOURCES/CONTEXTS: CONCLUDING REMARKS}

What insights does this book provide as regards the relationship of sales law with the diversity of sources, that can govern contracts of sale, and transactional/commercial contexts? So far as the relationship with industry sources is concerned, one key message of this book is that sales law should develop in a way that creates and promotes effective symbiosis between it and the industry sources. They complement one another and, taken together, provide a system of sources governing sales contracts in the modern world. The examples of such symbiosis can be found in the relationship of English law with the commodities standard form contracts, where the former is part and parcel of the meaning of the latter. Similar complementarity seems to have

\section{Ibid.}

92 Whereby, a documentary credit is treated as independent from an underlying contract, such as a contract of sale. See, eg, Art 4(a) UCP: 'A credit by its nature is a separate transaction from the sale or other contract on which it may be based. Banks are in no way concerned with or bound by such contract, even if any reference whatsoever to it is included in the credit. Consequently, the undertaking of a bank to honour, to negotiate or to fulfil any other obligation under the credit is not subject to claims or defences by the applicant resulting from its relationships with the issuing bank or the beneficiary. A beneficiary can in no case avail itself of the contractual relationships existing between banks or between the applicant and the issuing bank.'

93 Hare (n 89). 
emerged between the CISG and INCOTERMS. This close synergy means that there is also a reciprocal influence between the traditional sales law and industry sources. For example, English law seeks to facilitate trade and standardisation, including standardisation through standard form contracts, by adopting legal positions that are deemed to meet reasonable expectations of the relevant business community. Having largely developed in the commodities context, English sales law has arguably absorbed and acquired its distinctive 'commodities' character that emphasises speed, timing and legal certainty. At the same time, the trading communities follow carefully judicial decisions and where they disagree with the result, they respond by amending the relevant industry sources, such as their standard form contracts. As Bridge notes, "ii]f the courts, in the eyes of the trade, arrive at the wrong result, the "remedy" is an amendment of the relevant standard form, which after all amounts to a type of private legislation'. 94

Further, whilst the book shows the significance of industry sources, it also provides a word of caution. Commercial and sales law should be based on a sober assessment of, and not exaggerate, the actual role and standing of some such sources, as has been seen in the case of TUs. Care is even required with what appear to be well-developed standard form contracts. Bridge demonstrates the difficulties with some standard provisions concerning the passage of property in FOSFA standard form contracts on CIF terms. Does the multiplicity of sources lead to disintegration of sources of governance of sales contracts? 'No' is Spagnolo's answer, who argues that 'the array of combinations facilitated by this diversity [of sources] arguably enhances the capacity of ... sales laws to be utilized optimally'.95

A closely related question is how sales law should respond to the diversity of transactional and commercial contexts. This question is answered differently by the contributors. For example, Tettenborn's pragmatic argument in favour of the abstract calculation of damages, ${ }^{96}$ leading to 'rough justice' and promoting legal certainty, is well aligned with the already noted character of the commodities trade. However, an open question is whether this uncompromising pursuit of legal certainty is just as acceptable in radically different contexts, such as GSAs, which may well require law to exercise greater flexibility. Tettenborn's argument also provokes another broader and open question whether the law is capable of being well suited to all possible commercial/transactional contexts. If so, will the 'one-size-fits-all' approach prevent the law from having a distinctive identity and character, as English international sales law arguably has? ${ }^{97}$ Some advocates of the CISG might suggest that the relatively general character of its provisions make it universally capable of governing every conceivable sector. Schroeter's statement that the CISG's regime is in line 'with commercial practices and the needs of international trade' 98 refers to trade as a whole, with all its diversity, and therefore appears to reflect the belief in the 'universalist' powers of sales law.

\footnotetext{
94 Bridge (n 29).

95 Spagnolo (n 2).

96 Tettenborn (n 6).

97 It may also be asked whether sales law needs to have any distinctive character at all.

98 Schroeter (n 13).
} 


\section{Research handbook on international and comparative sale of goods law}

The book also reveals some contexts that may require sales law to continue to develop and be dynamic and 'open-minded' by embracing and adapting the peculiarities of the new technological and commercial developments. For instance, Green contends, in the context of digital material, that English law should pursue a 'progressive and responsive approach to interpreting ... the concept of sale' and be prepared to change its traditional 'conceptual landscape'. ${ }^{99}$ Similarly, Goldby highlights the fast-developing data storage systems to which the law may have to adapt. ${ }^{100}$ In the same spirit, Cafaggi suggests that, unless adapted or interpreted in a context-sensitive way, the traditional sales law regimes are not sufficiently well suited to governing sales contracts embedded in global supply chains. ${ }^{101}$ There may even be a need for a more radical approach of creating the international sales law regime(s) that is tailor made for the global supply chains. This point suggests the need for plurality of sales law regimes, which appears contrary to the earlier mentioned belief in the universal suitability of a well-developed sales law.

Given that many sectors are largely 'self-governed' through industry sources, it would appear that sales law does little in terms of governing the structuring and performance of transactions. This raises the question whether its purposes are largely confined to resolving disputes, providing the 'final stop' for allocating risks between the contracting parties by means of its default rules. This question remains open, but some contributors to this book would probably respond by saying that, even if so, the function of supplying default rules is very significant ${ }^{102}$ in terms of: providing filling gaps in areas that are not covered by the parties' contracts; promoting certainty and a useful starting framework for contract negotiations and drafting; reducing transaction costs by enabling parties to rely on default rules in negotiating and drafting contracts and ultimately promoting efficiency; encouraging or discouraging a particular behaviour. For all these reasons, it may well be the case, as one contributor argues, that default rules are 'a public good', the 'underutilization [of which] is inefficient' ${ }^{103}$

\footnotetext{
99 Green (n 72).

100 Goldby (n 77).

101 Cafaggi (n 66).

102 For the discussion of the significance of the law in terms of its providing detailed meaning of standard form contracts, see, generally, Bridge (n 29) and Gillette (n 19).

103 Spagnolo (n 2).
} 